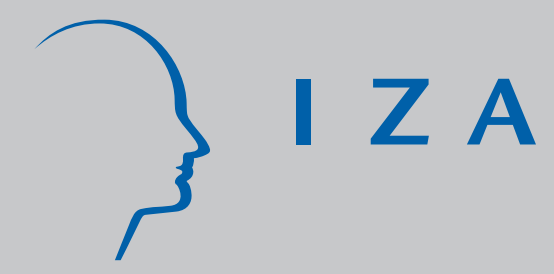

IZA DP No. 342

The Virtue of Being Underestimated: A Note on Discriminatory Contracts in Hidden Information Models

Wendelin Schnedler

August 2001 


\title{
The Virtue of Being Underestimated: A Note on Discriminatory Contracts in Hidden Information Models
}

\author{
Wendelin Schnedler \\ Department of Economics, Bonn Graduate School of Economics \\ and IZA, Bonn
}

Discussion Paper No. 342

August 2001

IZA

P.O. Box 7240

D-53072 Bonn

Germany

Tel.: +49-228-3894-0

Fax: +49-228-3894-210

Email: iza@iza.org

This Discussion Paper is issued within the framework of IZA's research area The Future of Work. Any opinions expressed here are those of the author(s) and not those of the institute. Research disseminated by IZA may include views on policy, but the institute itself takes no institutional policy positions.

The Institute for the Study of Labor (IZA) in Bonn is a local and virtual international research center and a place of communication between science, politics and business. IZA is an independent, nonprofit limited liability company (Gesellschaft mit beschränkter Haftung) supported by the Deutsche Post AG. The center is associated with the University of Bonn and offers a stimulating research environment through its research networks, research support, and visitors and doctoral programs. IZA engages in (i) original and internationally competitive research in all fields of labor economics, (ii) development of policy concepts, and (iii) dissemination of research results and concepts to the interested public. The current research program deals with (1) mobility and flexibility of labor markets, (2) internationalization of labor markets and European integration, (3) the welfare state and labor markets, (4) labor markets in transition, (5) the future of work, (6) project evaluation and (7) general labor economics.

IZA Discussion Papers often represent preliminary work and are circulated to encourage discussion. Citation of such a paper should account for its provisional character. 
IZA Discussion Paper No. 342

August 2001

\section{ABSTRACT \\ The Virtue of Being Underestimated: A Note on Discriminatory Contracts in Hidden Information Models"}

A standard hidden information model is considered to study the influence of the a priori productivity distribution on the optimal contract. A priori more productive (hazard rate dominant) agents work less, enjoy lower rents, but generate a higher expected surplus.

JEL Classification: D82, J71

Keywords: Adverse selection, statistical discrimination, stochastic order relation

Wendelin Schnedler

IZA

P.O. Box 7240

D-53072 Bonn

Germany

Tel.: +492283894121

Fax: +492283894510

Email: schnedler@iza.org

\footnotetext{
* The author wants to thank Georg Nöldecke, Urs Schweizer, and Stefan Napel for helpful comments. Financial support by DFG and IZA is gratefully acknowledged.
} 


\section{Introduction}

In the standard hidden information model which is described in many contract and game theory textbooks (Fudenberg and Tirole 1991, Salanié 1998, Schweizer 2000) and has been applied in many ways (see e.g. Melumand, Mookherjee, and Reichelstein 1995), a principal (e.g. an employer) offers an agent (e.g. a worker) a menu of work loads trying to elicit the latter's productivity. When designing the menu, the principal will rely on an a priori distribution of productivity. This distribution can be interpretated as the beliefs held by the employer about the productivity of the worker or as the distribution of productivity in a population from which the worker is randomly drawn. A difference in the a priori distribution for otherwise identically productive workers may lead to a different treatment of workers - an effect which is known as statistical discrimination and has firstly been described by Phelps (1973); for a recent overview see Altonji and Blank (1999).

Since statistical discrimination is based on the idea that workers cannot credibly signal their productivity so that employers have to rely on a priori distributions, the hidden information model constitutes a natural framework to study statistical discrimination. While the role of a priori distributions has been analysed for the hidden action model (Robbins and Sarath 1998), a similar task has not yet been accomplished for the hidden information model.

This note fills the gap by studying how a priori distributions affect three important variables of the hidden information model: expected profit accrueing to the principal, work loads assigned to and informational rents enjoyed by workers of a given productivity. To establish whether these variables are increasing or decreasing in the a priori distribution, we must be able to order distributions in some way. Then, we can make monotonicity statements based on two types of agents with orderable a priori distributions.

Suppose the employer observes a particular characteristic of the worker before proposing a menu of work loads; say workers can be red or blue. Assume that for some reason the productivity of blue agents is stochastically larger in a particular sense which we will define later, i.e. blue agents are a priori more productive. Then, one might be tempted to conclude that blue workers will be preferably hired, asked to work more, and be better paid than red workers. Indeed, it turns out that hiring a blue agent maximises the expected profit of the principal, but with respect to work loads and pay the intuition turns out to be false: if being hired, red agents of a given productivity get assigned more work and are better off than blue agents of the same productivity. 
The results can be motivated as follows: in order to convince an agent to reveal his true productivity, the principal has to pay an informational rent. This rent rises in the productivity of an agent and it increases in the work loads of agents with a lower productivity. Since there are more blue agents with a high productivity, costs of paying them their informational rents are higher than for red agents. To reduce these costs the principal chooses lower work loads for blue agents. Section 2 presencts the main findings and section 3 concludes.

\section{Hazard rate dominance and discrimination}

Consider a risk neutral principal and a risk neutral agent of colour $i \in\{R, B\}$ and productivity $\theta$. Let $B(a)$ the concave benefit function of the principal and $c(a, \theta)$ be the cost function of the agent when carrying out assignment $a$, where the costs are strictly convex in $a$, falling in $\theta$, and independent of the colour. Suppose that agents have quasi linear utilities and an outside option normalised to zero.

Now, the contract which maximises the principal's expected profit should be determined. By the revelation principle, it suffices to restrict attention to truth revealing contracts. Hence, we are looking for a direct mechanism prescribing the work assignment $a_{i}(\theta)$ and wage $x_{i}(\theta)$ for a worker of colour $i$ who has productivity $\theta$ which solves the following maximisation problem:

$$
\begin{aligned}
& \max _{\left(a_{i}(\theta), x_{i}(\theta)\right)} \mathrm{E}_{\Theta_{i}}\left[B\left(a_{i}\left(\Theta_{i}\right)\right)-x_{i}\left(\Theta_{i}\right)\right] \\
\text { such that } & \theta_{i} \in \operatorname{argmax}_{\theta} \quad x_{i}(\theta)-c\left(a_{i}(\theta), \theta\right) \\
\text { and } & x_{i}(\theta)-c\left({ }_{i}(\theta), \theta\right) \geq 0 \quad \forall \theta \in[\underline{\theta}, \bar{\theta}],
\end{aligned}
$$

where $\mathrm{E}_{\Theta_{i}}(\cdot)$ is the expected value operator applied over the random variable $\Theta_{i}$ describing the a priori productivity of an agent of colour $i$. Condition (2) ensures that all agents are willing to disclose their true productivity while condition (3) guarantees the participation of agents of all productivities.

In order to apply the machinery of the classical hidden information or adverse selection model, we suppose the single crossing property

$$
\frac{\partial^{2}}{\partial a \partial \theta} c(a, \theta)<0,
$$


and the following set of standard assumptions (Fudenberg and Tirole 1991, A8 on p. 263 and A10 on p. 267):

$$
\frac{\partial^{3}}{\partial a^{2} \partial \theta} c(a, \theta)<0, \quad \frac{\partial^{3}}{\partial a \partial \theta^{2}} c(a, \theta)>0, \quad \frac{\partial}{\partial \theta} \frac{1-F_{i}(\theta)}{f_{i}(\theta)}<0 .
$$

Under these assumptions, the solution to the problem defined by (1) to (3) is identical to the solution of the following simpler maximisation problem (Fudenberg and Tirole 1991, p. 265):

$$
\max _{a_{i}(\theta)} B\left(a_{i}(\theta)\right)-\underbrace{\left(c\left(a_{i}(\theta), \theta\right)-\frac{1-F_{i}(\theta)}{f_{i}(\theta)} \frac{\partial}{\partial \theta} c\left(a_{i}(\theta), \theta\right)\right)}_{=: h\left(a_{i}(\theta), \theta\right)} .
$$

The term $h\left(a_{i}(\theta), \theta\right)$ does not only contain a component to compensate for the exerted effort but also reflects the cost of eliciting the true productivity of the agent and is often referred to as virtual cost (see e.g. Salanié 1998).

The standard assumptions (4) and (5) also ensure that the objective function in (6) is concave, hence the solution to (6) can be obtained by the first order condition:

$$
\frac{\partial}{\partial a} B\left(a_{i}^{*}(\theta)\right)-\frac{\partial}{\partial a} c\left(a_{i}^{*}(\theta), \theta\right)+\frac{1-F_{i}(\theta)}{f_{i}(\theta)} \frac{\partial^{2}}{\partial a \partial \theta} c\left(a_{i}^{*}(\theta), \theta\right) \stackrel{!}{=} 0 .
$$

Next, we relate the productivity distributions of blue and red agents by declaring the a priori distribution of blue agents to hazard rate dominate the a priori distribution of red agents, if and only if

$$
\left.\frac{f_{B}(\theta)}{1-F_{B}(\theta)}<\frac{f_{R}(\theta)}{1-F_{R}(\theta)} \forall \theta \in\right] \underline{\theta} ; \bar{\theta}[,
$$

where $] \underline{\theta} ; \bar{\theta}[$ is the open subset of the common support of both distributions.

Intuitively, hazard rate dominance means the following: knowing that an agent has a productivity above $\theta$, the probability of encountering a red agent of a productivity in a tiny interval above $\theta$ is larger than the probability of encountering a blue agent. For this to be true, the distribution of blue agents must have relatively more probability mass to the right. Hence, it is justified to call blue agents "a priori more productive".

As an illustration of hazard rate dominance consider the following example: blue agents' productivity is uniformly distributed between zero and one while the cumulative distribution function of red agents' is:

$$
F_{R}(\theta)=\theta(2-\theta) \quad \forall \theta \in[0,1] .
$$


The respective densities and distributions are depicted in figure 1.
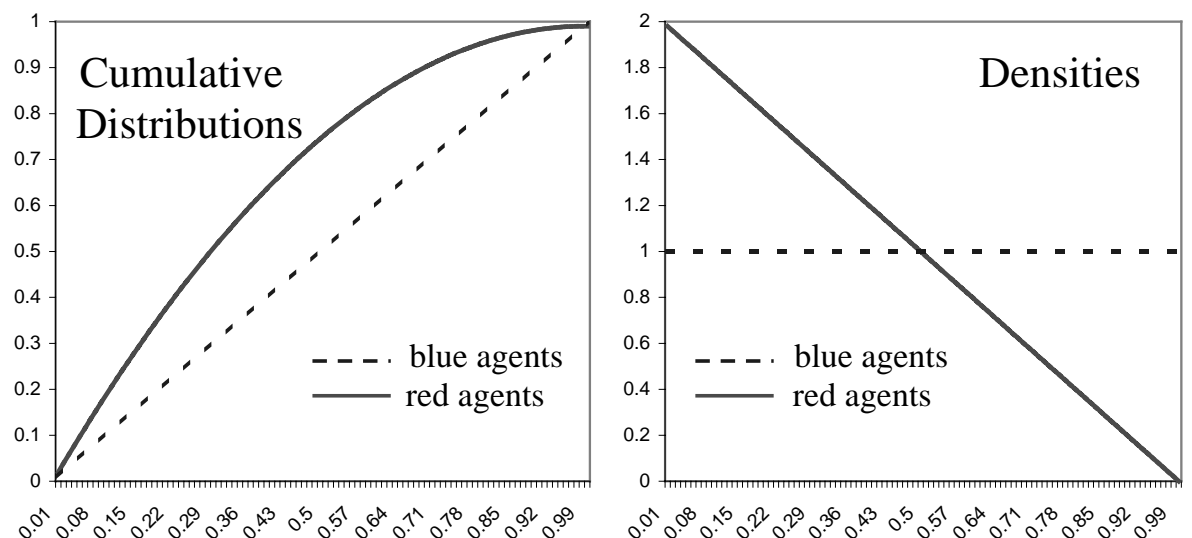

Figure 1: Distributions and Densities

In this example, blue agents' productivity also first order stochastic dominates red agents' productivity, which raises the question, how hazard rate dominance relates to first order stochastic dominance. A simple answer is given by the following result.

Result 1. If $f_{B}(\cdot)$ and $f_{R}(\cdot)$ are continuous and $F_{B}(\theta)$ hazard rate dominates $F_{R}(\theta)$ then $F_{B}(\theta)$ first order stochastically dominates $F_{R}(\theta)$.

Proof. See appendix.

Like first order stochastic dominance, hazard rate dominance induces no complete ordering of distributions; as it is a stronger concept, the class of distribution pairs which can be ordered is even smaller. For an alternative proof of Result 1 and an elaborate overview on stochastic orders, the reader may consult Müller and Stoyan (forthcoming).

Now, we will use the notion of hazard rate dominance to make a statement about work assignment differences between blue and red agents. By considering the maximisation problem expressed as (6), we observe that hazard rate dominance directly leads to lower virtual costs for the dominated type at all productivities. Since the converse is also true, hazard rate dominance turns out to be a necessary and sufficient condition for lower optimal production assignments: 
Result 2. Given assumptions (4) and (5), the optimal production assignment $a_{B}^{*}(\theta)$ is lower than $a_{R}^{*}(\theta)$ for all $\left.\theta \in\right] \underline{\theta}, \bar{\theta}\left[\right.$ if and only if $F_{B}(\cdot)$ hazard rate dominates $F_{R}(\cdot)$.

Proof. By (4) and (5), it follows that (6) is uniquely maximised in $a_{R}^{*}$ and $a_{B}^{*}$ for the respective a priori distributions. Adding the inequalities describing these maximum properties, we get:

$-\frac{\partial}{\partial \theta} c\left(a_{R}^{*}(\theta), \theta\right)\left(\frac{1-F_{R}(\theta)}{f_{R}(\theta)}-\frac{1-F_{B}(\theta)}{f_{B}(\theta)}\right)>-\frac{\partial}{\partial \theta} c\left(a_{B}^{*}(\theta), \theta\right)\left(\frac{1-F_{R}(\theta)}{f_{R}(\theta)}-\frac{1-F_{B}(\theta)}{f_{B}(\theta)}\right)$.

Given (4), the second factor is increasing in $a$. Hazard rate dominance implies that the first factor is positive, so that $a_{R}^{*}>a_{B}^{*}$. Conversely, $a_{R}^{*}>a_{B}^{*}$ implies that the second factor on the right hand side is smaller than that on the left, so that the first factor must be positive.

In general, the payment $x_{i}$ to an agent of colour $i$ consists of two elements: a compensation for the effort costs and an informational rent. The functional form of the payment looks as follows (Salanié 1998, p.34):

$$
x_{i}(\theta)=\underbrace{c\left(a_{i}^{*}(\theta), \theta\right)}_{\text {compensation }} \underbrace{-\int_{\underline{\theta}}^{\theta} \frac{\partial}{\partial \theta} c\left(a_{i}^{*}(t), t\right) d t}_{\text {informational rent }} .
$$

Since effort costs and compensation cancel, utility between agents of different colour only differs with respect to informational rents. By the single crossing property (4), the integrand in the informational rent term (9) gets smaller when the assignment $a$ increases; minus the integrand gets larger and so does the informational rent which is the integral over these terms. By result 2 red agents get larger assignments and we can state:

Corollary 1. Given assumptions (4) and (5), a red agent of productivity $\theta$ enjoys a higher utility than a blue agent of the same productivity for all $\theta \in] \underline{\theta}, \bar{\theta}\left[\right.$ if and only if $F_{B}(\cdot)$ hazard rate dominates $F_{R}(\cdot)$. 
Proof. Red agents enjoy higher utility iff for all $\theta \in] \underline{\theta}, \bar{\theta}[$ :

$$
\begin{array}{rll} 
& x_{R}(\theta)-c\left(a_{R}^{*}(\theta), \theta\right) & >x_{B}(\theta)-c\left(a_{B}^{*}(\theta), \theta\right) \\
\Leftrightarrow \forall \theta \in] \underline{\theta}, \bar{\theta}\left[: \int_{\underline{\theta}}^{\bar{\theta}}-\frac{\partial}{\partial \theta} c\left(a_{R}^{*}(t), t\right) d t\right. & >\int_{\underline{\theta}}^{\bar{\theta}}-\frac{\partial}{\partial \theta} c\left(a_{B}^{*}(t), t\right) d t \\
\Leftrightarrow \forall \theta \in] \underline{\theta}, \bar{\theta}\left[: \quad-\frac{\partial}{\partial \theta} c\left(a_{R}^{*}(t), t\right)\right. & >-\frac{\partial}{\partial \theta} c\left(a_{B}^{*}(t), t\right) \\
\Leftrightarrow \forall \theta \in] \underline{\theta}, \bar{\theta}\left[: \quad a_{R}^{*}(\theta)\right. & >a_{B}^{*}(\theta),
\end{array}
$$

where the latter is true by Result 2 iff blue hazard rate dominates red.

Finally, we want to answer the question what colour the principal prefers.

Result 3. Given assumptions (4) to (5) and that $F_{B}(\cdot)$ hazard rate dominates $F_{R}(\cdot)$, blue agents generate a higher expected profit.

Proof. Denote the profit generated by the agent of productivity $\theta$ carrying out assignment $a$ by $\pi(a, \theta)$. Note, that the constraints (3) and (2) are independent from the distribution, so that assigning $a_{R}^{*}(\theta)$ to blue agents does not violate those constraints. As this assignment is not optimal, we get: $\mathrm{E}_{B}\left[\pi\left(a_{B}^{*}(\theta), \theta\right)\right]>\mathrm{E}_{B}\left[\pi\left(a_{R}^{*}(\theta), \theta\right)\right]$. If profits are increasing in $\theta$, hazard rate dominance implies $\mathrm{E}_{B}\left[\pi\left(a_{R}^{*}(\theta), \theta\right)\right]>\mathrm{E}_{R}\left[\pi\left(a_{R}^{*}(\theta), \theta\right)\right]$ and we are done. To show that profits increase in $\theta$, we take their derivative:

$$
\left(\frac{\partial B\left(a_{i}^{*}(\theta)\right)}{\partial a}-\frac{\partial c\left(a_{i}^{*}(\theta), \theta\right)}{\partial a_{i}}\right) \frac{\partial a_{i}(\theta)}{\partial \theta}>0,
$$

where the first factor is positive by (7) and the second factor is positive due to the strict concavity implied by (4) and (5) and the fact that for incentive compatible mechanisms assignments must be increasing in productivity (Salanié, p. 31).

The assumptions in this result can be considerably relaxed (see appendix); here, it is presented in a less general but more coherent version.

\section{Conclusion}

We examined two distinctive types of agents who only differed with respect to their a priori distribution of productivity. Ranking these distributions so 
that one type is a priori more productive according to a relation called hazard rate dominance enabled us to establish a link between a priori productivity and three important variables in the hidden information model: expected profit, work assignments, and informational rents.

Not surprisingly, the principal prefers a priori more productive agents. If, however, agents with a lower a priori productivity are employed, they get larger work assignements than their a priori more productive homologues and enjoy higher informational rents. In this sense, being underestimated is advantagous.

\section{References}

Altonji, J. G., And R. Blank (1999): "Race and Gender in the Labor Market," in Handbook of Labor Economics, ed. by O. Ashenfelter, and D. Card, vol. 3, pp. 3143-3259. Elsevier B.V., Amsterdam.

FudenberG, D., And J. Tirole (1991): Game Theory. The MIT Press, Cambridge, Massachusetts.

Melumad, N. D., D. Mookherjee, and S. Reichelstein (1995): "Hierarchical Decentralization of Incentive Contracts," RAND Journal of Economics, 26(4), 654-672.

MÜller, A., And D. Stoyan (forthcoming): "Univariate Stochastic Order Relations," "Comparison Methods for Stochastic Models and Risks", John Wiley and Sons, forthcoming.

Phelps, E. S. (1973): "The Statistical Theory of Racism and Sexism," American Economic Review, 62(4), 659-661.

Robbins, E. H., And B. Sarath (1998): "Ranking Agencies Under Moral Hazard," Economic Theory, 11(1), 129-155.

SAlanié, B. (1998): Economics of contracts. MIT Press.

SchweIZER, U. (2000): Ökonomische Theorie der Verträge. Mohr (Siebeck), Tübingen. 


\section{Appendix}

The following lemma is needed to proof Result 1 .

Lemma 1. If $f_{R}(\cdot)$ and $f_{B}(\cdot)$ are continuous density functions with the same support, then there exists a $\tilde{\theta} \in] \underline{\theta}, \bar{\theta}\left[\right.$ such that $f_{R}(\tilde{\theta})=f_{B}(\tilde{\theta})$.

Proof. Suppose that $\tilde{\theta}$ would not exist, then $\left.f_{R}(\theta)>f_{B}(\theta) \forall \theta \in\right] \underline{\theta}, \bar{\theta}[$ without loss of generality. Integrating over the whole support, we get $\int_{\Omega} f_{R}(t) d t>$ $\int_{\Omega} f_{B}(t) d t=1$, where the inequality is a contradiction to the claim of $f_{R}(\cdot)$ being a density function.

\section{Proof of Result 1}

We want to show that hazard rate dominance implies first order stochastic dominance. The proof will be carried out in two steps. First, we will show that $F_{R}(\theta)$ is larger than $F_{B}(\theta)$ for small $\theta$, afterwards we prove that $F_{R}(\cdot)$ and $F_{B}(\cdot)$ can never intersect.

\section{Step 1}

By lemma 1 , exists a $\tilde{\theta} \in] \underline{\theta}, \bar{\theta}\left[\right.$, such that $0<f_{R}(\tilde{\theta})=f_{B}(\tilde{\theta})$. Pick the smallest such $\tilde{\theta}$. Using the hazard rate dominance, one gets: $1-F_{B}(\tilde{\theta})>$ $1-F_{R}(\tilde{\theta}) \Leftrightarrow F_{B}(\tilde{\theta})<F_{R}(\tilde{\theta})$, which implies

$$
\forall \underline{\theta}<\theta<\tilde{\theta}: f_{R}(\theta)>f_{B}(\theta) \text { and } \forall \underline{\theta}<\theta<\tilde{\theta}: F_{R}(\theta)>F_{B}(\theta) .
$$

\section{Step 2}

Now, suppose there exists an intersection between $F_{R}(\cdot)$ and $F_{B}(\cdot)$ at $\theta^{\prime}$. Pick the smallest $\theta^{\prime}$. Once again by the hazard rate dominance, we get: $f_{B}\left(\theta^{\prime}\right)<f_{R}\left(\theta^{\prime}\right)$. This, however, implies that

$$
F_{B}\left(\theta^{\prime \prime}\right)>F_{R}\left(\theta^{\prime \prime}\right)
$$

for some $\theta^{\prime \prime}$ arbitrarily close but below $\theta^{\prime}$.

If $\theta^{\prime}$ is smaller or equal to $\tilde{\theta}$ from step one, we get a contradiction to (10). If $\theta^{\prime}$ is larger than $\tilde{\theta}$, then continuity of $F_{B}(\cdot)$ and $F_{R}(\cdot)$ together with 
equations (10) and (11) assure the existence of a $\theta^{\prime \prime \prime} \in\left(\tilde{\theta}, \theta^{\prime \prime}\right)$ such that $F_{B}\left(\theta^{\prime \prime \prime}\right)=F_{R}\left(\theta^{\prime \prime \prime}\right)$. But this is a contradiction to the $\theta^{\prime}$ being the smallest such value.

Overall, we cannot hold the supposition that there is an intersection between $F_{R}(\cdot)$ and $F_{B}(\cdot)$. By equation (10), it must then be true that

$$
\forall \theta \in] \underline{\theta}, \bar{\theta}\left[: \quad F_{B}(\theta)<F_{R}(\theta) .\right.
$$

\section{Proof of a milder version of Result 3}

Result 4. Given assumption (4) and $F_{B}(\theta) \leq F_{R}(\theta)$, blue agents generate a larger expected surplus: $E_{B}\left[\pi\left(a_{B}(\theta), \theta\right)\right] \geq E_{R}\left[\pi\left(a_{R}(\theta), \theta\right)\right]$, where equality holds if and only if the optimal assignments to blue and red agents are identical on all open sets and $\frac{F_{B}(\theta)}{F_{B}\left(\theta_{U}\right)-F_{B}\left(\theta_{L}\right)} \geq \frac{F_{R}(\theta)}{F_{R}\left(\theta_{U}\right)-F_{R}\left(\theta_{L}\right)}$ on any interval ]$\theta_{U} ; \theta_{L}\left[\right.$ where $a_{R}(\theta)$ is strictly increasing.

Proof. Since the mechanism must be incentive compatible and the single crossing property holds, the optimal $a_{i}$ must be a non decreasing function in $\theta$ (see e.g. Fudenberg and Tirole (1991) Theorem 7.2). First, we want to show that this implies monotone increasing profits. Suppose, profits would fall close to $\left.\left.\theta^{\prime}: \pi\left(a_{i}(\theta), \theta\right)<\pi\left(a_{i}\left(\theta^{\prime}\right), \theta^{\prime}\right) \forall \theta \in\right] \theta^{\prime} ; \theta^{\prime \prime}\right]$. Consider the incentive mechanism where all types between $\theta^{\prime}$ and $\theta^{\prime \prime}$ get the assignment $\tilde{a}_{i}=a_{i}\left(\theta^{\prime}\right)$ and receive the payment $\tilde{x}_{i}(\theta)=-\int_{\underline{\theta}}^{\theta^{\prime}} \frac{\partial}{\partial \theta} c\left(a_{i}(t), t\right) d t+c\left(a_{i}\left(\theta^{\prime}\right), \theta^{\prime}\right)$, whereas assignments and payments stay the same for all agents below $\theta^{\prime}$ and agents larger $\theta^{\prime \prime}$ keep their old assignment and get $-\int_{\underline{\theta}}^{\theta^{\prime}} \frac{\partial}{\partial \theta} c\left(a_{i}(t), t\right) d t+c\left(a\left(\theta^{\prime}\right), \theta^{\prime}\right)-$ $c\left(a\left(\theta^{\prime \prime}\right), \theta^{\prime \prime}\right)-\int_{\theta^{\prime \prime}}^{\theta} \frac{\partial}{\partial \theta} c\left(a_{i}(t), t\right) d t+c\left(a_{i}(\theta), \theta\right)$. This mechanism fulfills participation and incentive constraints. Moreover, the mechanism leads to larger or equal profits for all $\theta>\theta^{\prime}$. In particular, the profit generated by $\theta^{\prime \prime}$ is identical to the profit generated by $\theta^{\prime}$. Hence, the profit under optimal assignments can't be decreasing and due to the first order stochastic dominance, we get:

$$
\mathrm{E}_{B}\left[\pi\left(a_{R}(\theta), \theta\right)\right] \geq \mathrm{E}_{R}\left[\pi\left(a_{R}(\theta), \theta\right)\right] .
$$

If the optimal $a_{i}$ chosen for $\theta^{\prime \prime}$ is strictly larger than that for $\theta^{\prime}$, the profit for $\theta^{\prime \prime}$ must be strictly larger as well. Given there is some interval $] \theta_{U} ; \theta_{L}[$ 
where $a_{R}$ is strictly monotone, then $\pi_{R}$ is strictly monotone on this set and if additionally blue agents have more probability mass to the right $\left(\frac{F_{B}(\theta)}{F_{B}\left(\theta_{U}\right)-F_{B}\left(\theta_{L}\right)}<\frac{F_{R}(\theta)}{F_{R}\left(\theta_{U}\right)-F_{R}\left(\theta_{L}\right)}\right)$, the inequality is strict.

Since the incentive and participation constraint are independent from the distribution, giving blue agents the assignments of red agents is feasible (although not necessarily optimal) and hence

$$
\mathrm{E}_{B}\left[\pi\left(a_{B}(\theta), \theta\right)\right] \geq \mathrm{E}_{B}\left[\pi\left(a_{R}(\theta), \theta\right)\right]
$$

If there is an open set where assignments between blue and red agents differ, the strict inequality will hold. Putting (13) and (14) together, we obtain the result. 


\section{IZA Discussion Papers}

$\begin{array}{ll}\text { No. } & \text { Author(s) } \\ 260 & \begin{array}{l}\text { P. Cahuc } \\ \text { F. Postel-Vinay }\end{array} \\ 261 & \text { M. Lindahl }\end{array}$ Communism: Some Empirical Evidence 

A. Kaul
M. Kolmar

Efficiency Properties of Labor Taxation in a 

and the Rising Returns to Skill: US and France 1964-2000 

H. Bonin
G. Abío
E. Berenguer
J. Gil
C. Patxot

307

G. A. Pfann

308

G. A. Pfann

D. S. Hamermesh

309
G. Brunello

310

U. Sunde

M. Kemler

G. A. Pfann 

A. Frederiksen
E. K. Graversen
N. Smith

Germany: The Impact on Productivity and Wages Model 

Quality
A. Ibourk
B. Maillard
S. Perelman
H. R. Sneessens

The Matching Efficiency of Regional Labour Markets: A Stochastic Production Frontier

Estimation, France 1990-1995

340

$$
\begin{aligned}
& \text { X. Wauthy } \\
& \text { Y. Zenou }
\end{aligned}
$$

How Does Imperfect Competition in the Labor 